\title{
Review Article \\ Human Papillomavirus Infection as a Possible Cause of Spontaneous Abortion and Spontaneous Preterm Delivery
}

\author{
Lea Maria Margareta Ambühl, ${ }^{1}$ Ulrik Baandrup, ${ }^{1}$ Karen Dybkær, ${ }^{2}$ Jan Blaakær, ${ }^{3}$ \\ Niels Uldbjerg, ${ }^{3}$ and Suzette Sørensen ${ }^{1}$ \\ ${ }^{1}$ Center for Clinical Research, North Denmark Regional Hospital and Department of Clinical Medicine, \\ Aalborg University, Bispensgade 37, 9800 Hjørring, Denmark \\ ${ }^{2}$ Department of Hematology, Aalborg University Hospital, Søndre Skovvej 15, 9000 Aalborg, Denmark \\ ${ }^{3}$ Department of Obstetrics and Gynecology, Aarhus University Hospital, Palle Juul-Jensens Boulevard 99, 8200 Aarhus N, Denmark
}

Correspondence should be addressed to Suzette Sørensen; suzette.soerensen@rn.dk

Received 18 December 2015; Revised 10 March 2016; Accepted 13 March 2016

Academic Editor: Susan Cu-Uvin

Copyright (C) 2016 Lea Maria Margareta Ambühl et al. This is an open access article distributed under the Creative Commons Attribution License, which permits unrestricted use, distribution, and reproduction in any medium, provided the original work is properly cited.

\begin{abstract}
Based on the current literature, we aimed to provide an overview on Human Papillomavirus prevalence in normal pregnancies and pregnancies with adverse outcome. We conducted a systematic literature search in PubMed and Embase. Data extracted from the articles and used for analysis included HPV prevalence, pregnancy outcome, geographical location, investigated tissue types, and HPV detection methods. The overall HPV prevalence in normal full-term pregnancies was found to be 17.5\% (95\% CI; 17.3-17.7) for cervix, 8.3\% (95\% CI; 7.6-9.1) for placental tissue, 5.7\% (95\% CI; 5.1-6.3) for amniotic fluid, and 10.9\% (95\% CI; 10.1-11.7) for umbilical cord blood. Summary estimates for HPV prevalence of spontaneous abortions and spontaneous preterm deliveries, in cervix (spontaneous abortions: $24.5 \%$, and preterm deliveries: $47 \%$, resp.) and placenta (spontaneous abortions: $24.9 \%$, and preterm deliveries: 50\%, resp.), were identified to be higher compared to normal full-term pregnancies $(P<0.05$ and $P<0.0001)$. Great variation in HPV prevalence was observed between study populations of different geographical locations. This review demonstrates an association between spontaneous abortion, spontaneous preterm delivery, and the presence of HPV in both the cervix and the placenta. However, a reliable conclusion is difficult to draw due to the limited number of studies conducted on material from pregnancies with adverse outcome and the risk of residual confounding.
\end{abstract}

\section{Introduction}

Intrauterine infection by bacteria is well established as a pathway leading to spontaneous abortion and spontaneous preterm birth $[1,2]$. Other pathways, however, may be equally important including decidual hemorrhage, cervical disorders, genetic components, and environmental exposures like smoking [3]. Much less is known about viral infection and adverse pregnancy outcome. Human Papillomavirus (HPV), which is known as a well-established cause for cervical cancer, does though constitute a candidate. The over 180 known HPV-types are small, double-stranded DNA viruses with a circular genome of nearly 8,000 base pairs. HPV infections are common, but about $90 \%$ of all infections can be cleared within less than 2 years by unknown mechanisms [4-6].
HPV-6 and HPV-11 are the most common low-risk types and are found to be causative for genital warts [6]. The cancer associated high-risk types include HPV-16 and HPV-18 [6] and there is growing evidence of HPV infections playing a relevant role in other anogenital and head and neck cancers [7-9]. Worth to mention is also the morbidity of cutaneous HPV lesions, particularly in immunosuppressed people [9].

Pregnancy has previously proven to be a state of mild immunosuppression due to the decrease in the number of natural killer cells [10], possibly making pregnant women more prone to infections with, for example, HPV. Various immunological theories have been discussed to explain the possibility for pregnancy and the survival of the "semiallogeneic" fetus. Theories include immunological privilege in the uterus, antigenic immaturity of the fetus, and maternal 
immunosuppression during pregnancy [11]. While attempting to explain the immunological basis of normal pregnancy, the argumentation may have implications for the generation of immune responses to pathogens infecting the placenta, as viruses seem to face similar confrontations like the invading trophoblast [11]. Thus, it is not surprising that viruses take up some of the same strategies to avoid immune detection as do trophoblast cells [12]. Also there is some evidence that elevated steroid hormone levels during pregnancy influence the increase of HPV virus replication by interacting with hormone response elements in the viral genome, thereby giving another possible explanation for the higher incidence of HPV infection during pregnancy [13, 14]. In 2014, Liu et al. [15] conducted a systematic review on HPV prevalence in pregnant and nonpregnant women and reported an increased risk of $\mathrm{HPV}$ infection in pregnant women, thereby supporting the debate of how far HPV may be involved in adverse pregnancy outcomes. Various authors report an infection with HPV during pregnancy to be associated with the risk of spontaneous abortion, spontaneous preterm delivery, and placental abnormalities [16-21]. HPV DNA has been detected in the cervix [13, 21-23], fetal membranes [24], amniotic fluid [25], umbilical cord blood [26, 27], and the placenta [13, 18, 27-29]. HPV detection rates range however widely from 6 to $65 \%$ and the results are controversial [13, 18, 20, 22, 23, 27, 30-32].

It is therefore of great interest to examine how widespread HPV infections are among pregnant women and whether or not there is an association between HPV infection and spontaneous abortion or spontaneous preterm delivery. Moreover, nowadays there exists a successful vaccination to prevent infection and disease caused by infection with HPV6, HPV-11, HPV-16, and HPV-18. Thus, there might be a chance to minimize the risk for pregnancy complications by applying the same or a modified version of vaccination. Our group studies the impact of placental HPV infection on spontaneous abortion and preterm delivery. In this context the aim of this study is to provide an overview of the existing literature by doing a systematic review on HPV prevalence in pregnancy. We focused on pregnancies with adverse outcome and included a discussion of possible factors influencing or explaining the reported differences in HPV detection rates.

\section{Material and Methods}

PRISMA and MOOSE guidelines were used where applicable [33].

2.1. Search Strategy. A systematic literature search was conducted in the PubMed and Embase databases and search terms were used as follows: (1) "Human papillomavirus AND pregnancy"; (2) "Human papillomavirus AND preterm delivery"; (3) "Human papillomavirus AND preterm birth"; (4) "Human papillomavirus AND abortion". The search was restricted to articles in English, on humans and published between January 1995 and October 2014. The search was carried out on October 28, 2014.

2.2. Study Selection. In order to identify relevant articles for whole-paper revision, duplicates were removed and titles and abstracts were screened based on the following exclusion criteria: studies investigating cell lines only, HPV vaccines, or sperm-related aspects, as well as guideline articles, general articles describing public health, and literature reviews. The remaining articles were assigned to subsequent whole-paper revision. These articles were systematically reviewed in accordance with the inclusion and exclusion criteria. The inclusion criteria were set to the following: studies on asymptomatic healthy pregnant women and women experiencing a spontaneous preterm delivery or spontaneous abortion; investigation of HPV infection within cervix, placenta, amniotic fluid, or umbilical cord blood; HPV detection test directly linkable to index pregnancy. Studies restricted to nonpregnant women or HPV positive women only, case reports, follow-up and association studies, and in vitro fertilization studies were excluded.

Studies including women with history of HPV-related lesions were not excluded, as this will be the case in any normal study population. There was no restriction for studies of different geographical origins, the time point of sample collection, methods of sample collection, and HPV testing method. Information on the latter was included in Table 1, characteristics of included studies.

2.3. Data Extraction and Statistics. Data, which includes information about the investigated tissue types, country where the study was performed, sample size, sampling time point, HPV prevalence, and HPV detection method, was extracted and analyzed using MatLab (version R2011b). Data from all studies was pooled and women were grouped according to their pregnancy outcome or the pregnancy status at time point of sample collection. An overall HPV prevalence was calculated including 95\% confidence interval (CI) in normal pregnancies and in pregnancies with adverse outcome. This was done for various tissue types, geographical origins, time points of sample collection, and HPV detection methods used. Studies from Mexico and Brazil have been grouped into "Latin America." Statistical significance between two proportions was tested using "Two-sample test of proportions." All $P$ values were two-sided and $P<0.05$ was considered significant.

\section{Results}

3.1. Study Selection. The initial PubMed database search resulted in the identification of a total of 650 articles (Figure 1). After removal of duplicates and screening of titles and abstracts, the remaining 57 articles were subjected to whole-paper revision (Figure 1). Of these, 42 articles met the final inclusion criteria and were used for data extraction and quantitative analyses (Figure 1). The supplementary search in Embase database was conducted in the same way and three additional articles were included for data extraction and quantitative analysis. The 45 articles included investigated 14470 pregnant women in total, of which 13757 underwent normal full-term pregnancies, 145 experienced spontaneous preterm deliveries, 536 experienced spontaneous abortions, and 32 had performed an induced abortion. The study populations were from Europe $(n=4639)[13,22,27,28$, 


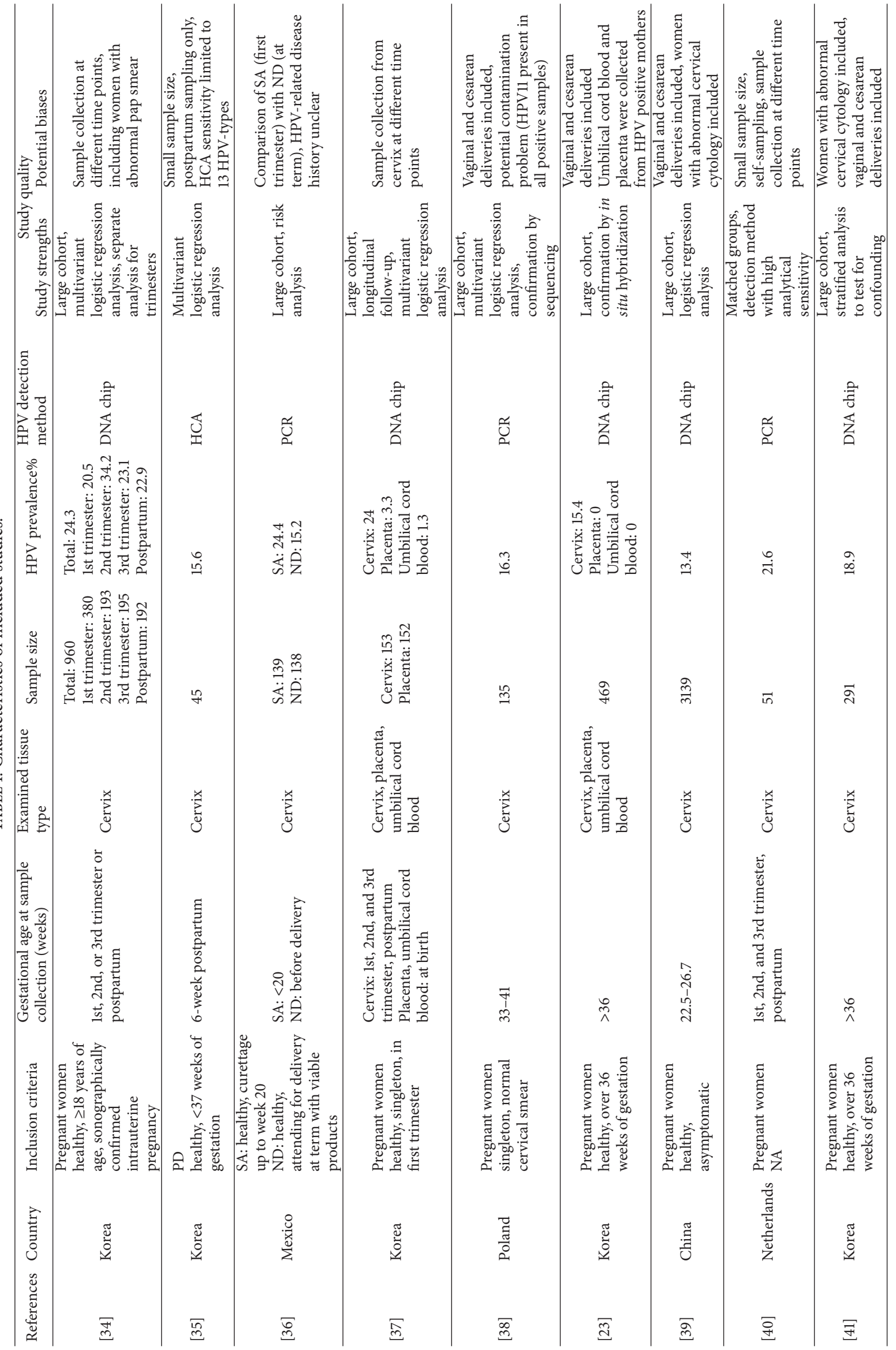




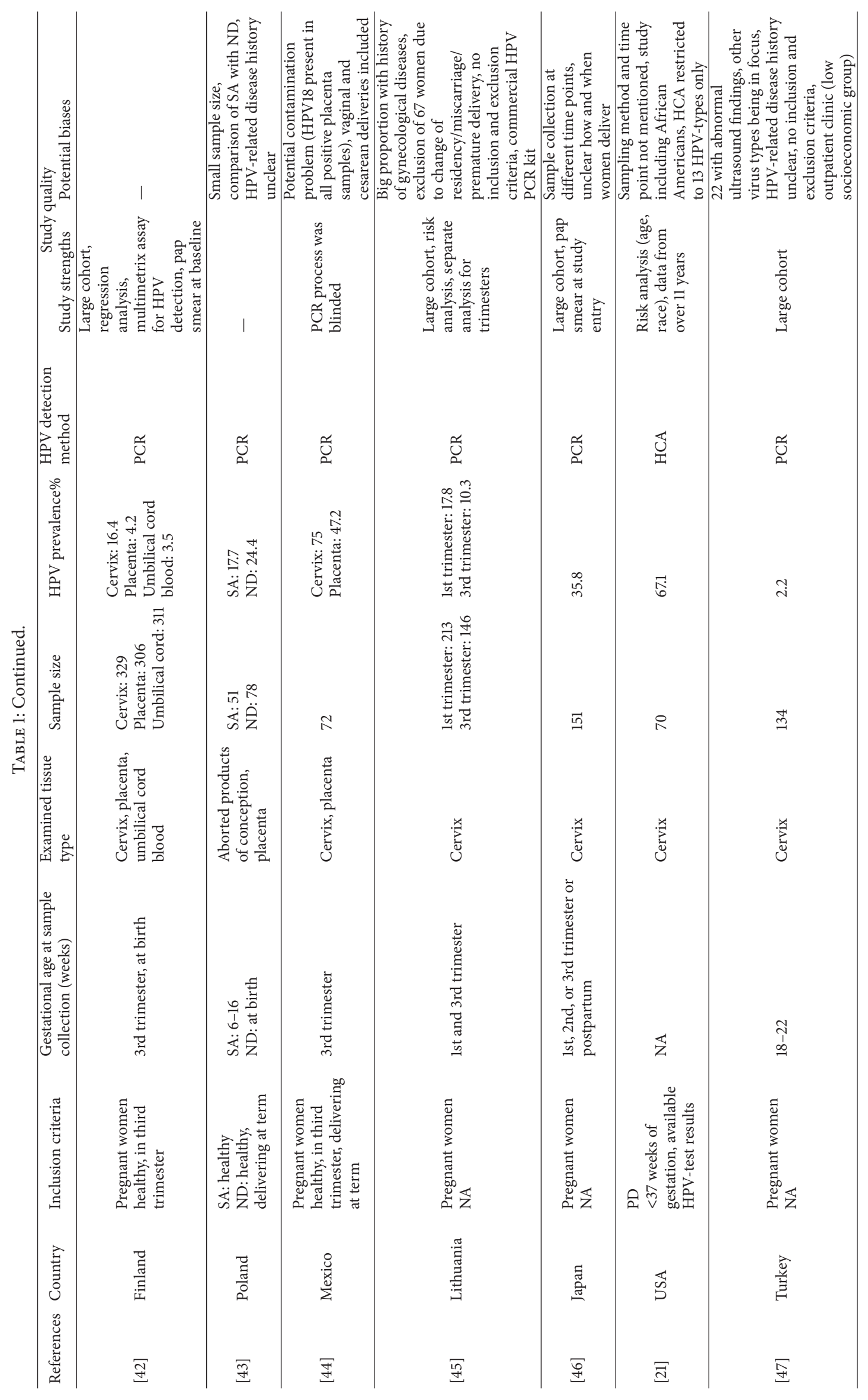




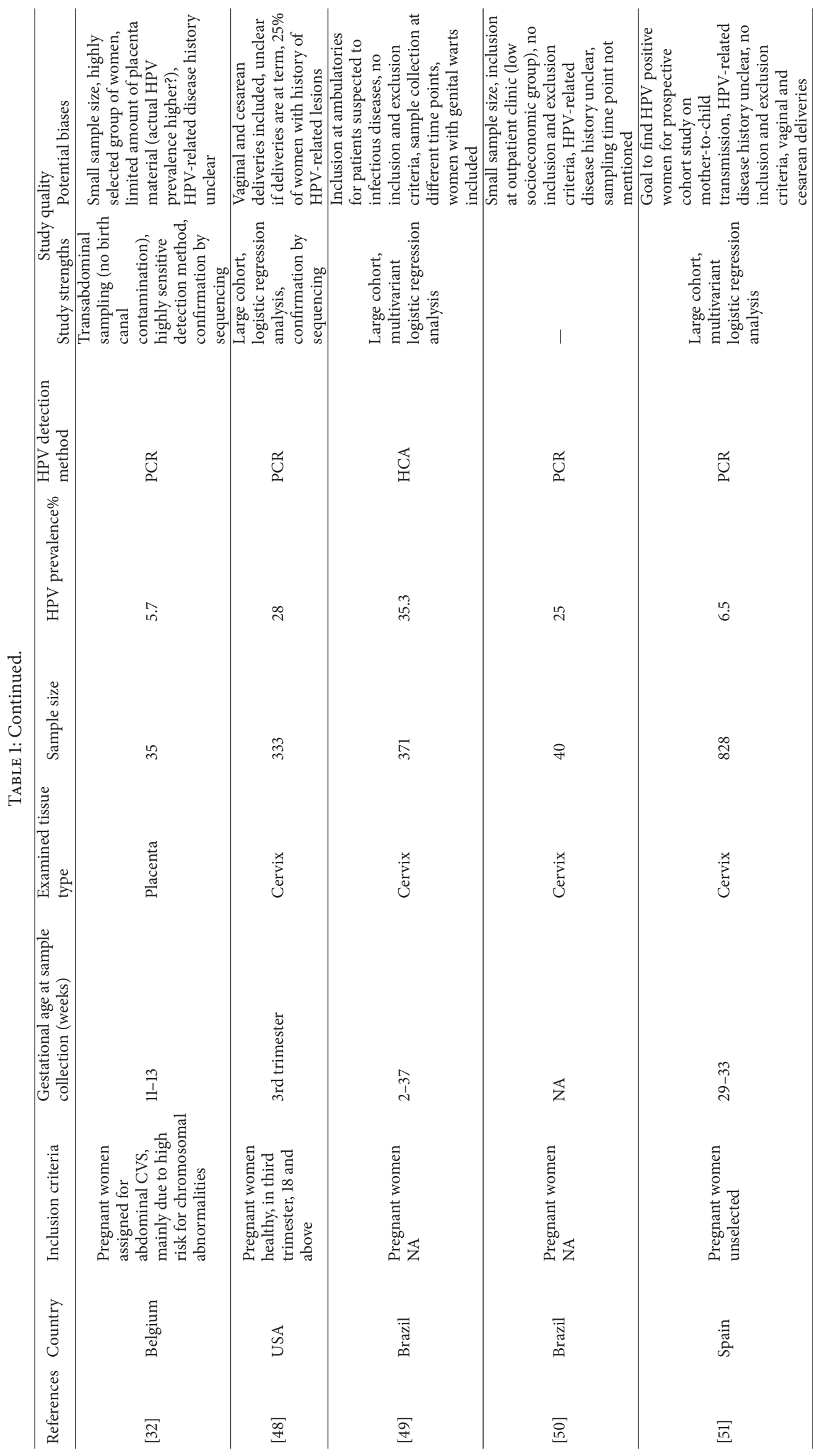




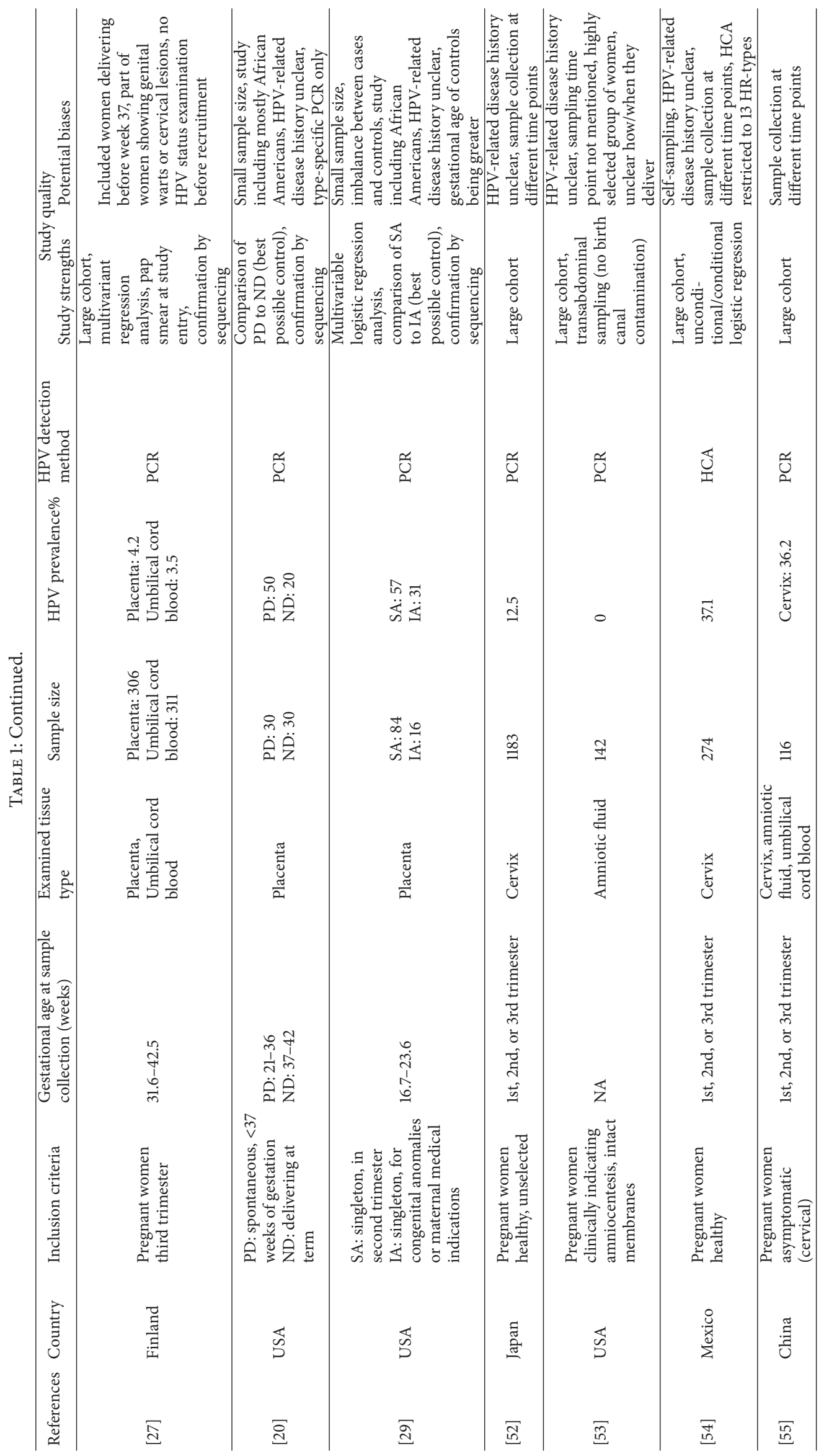




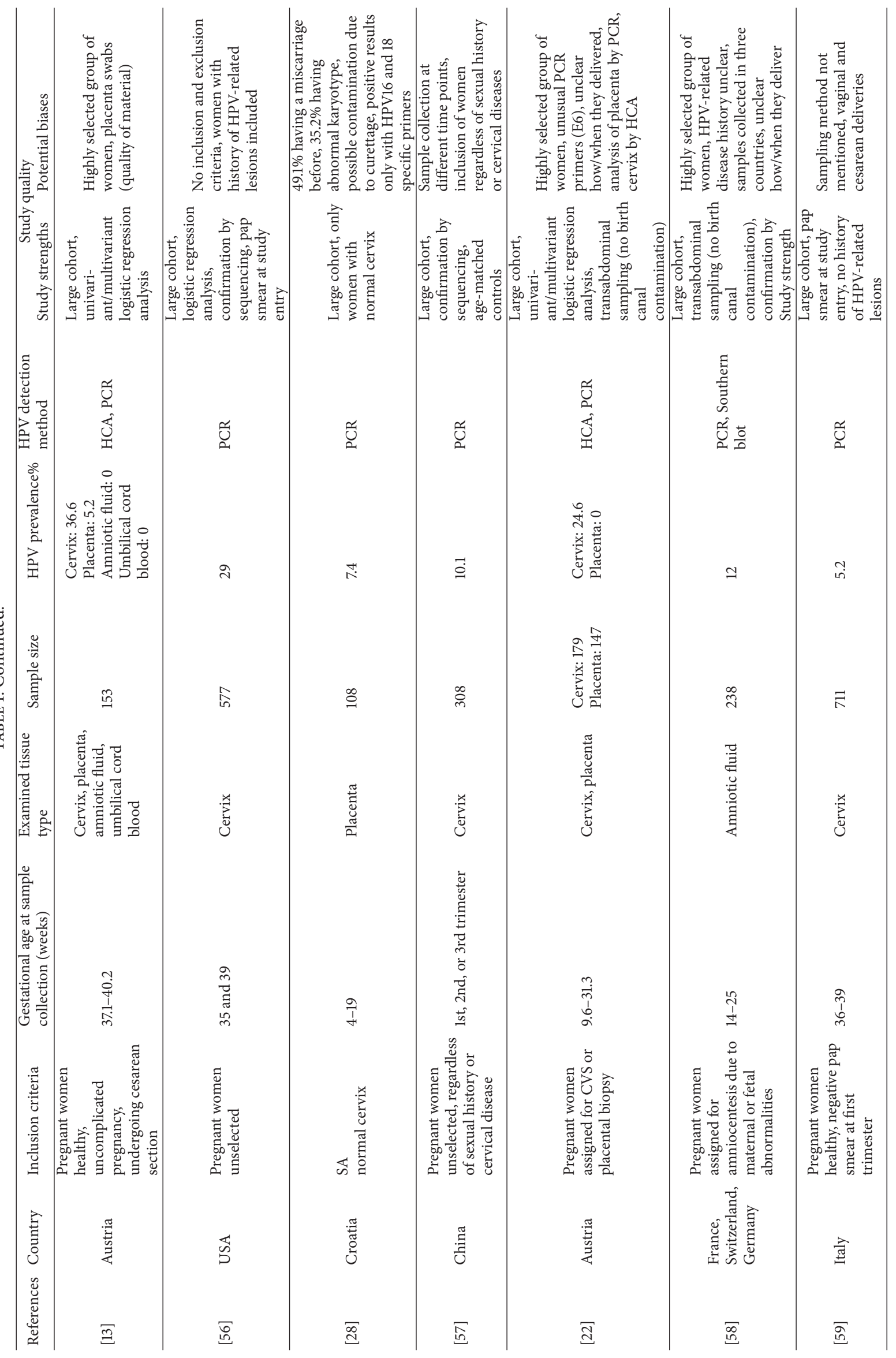




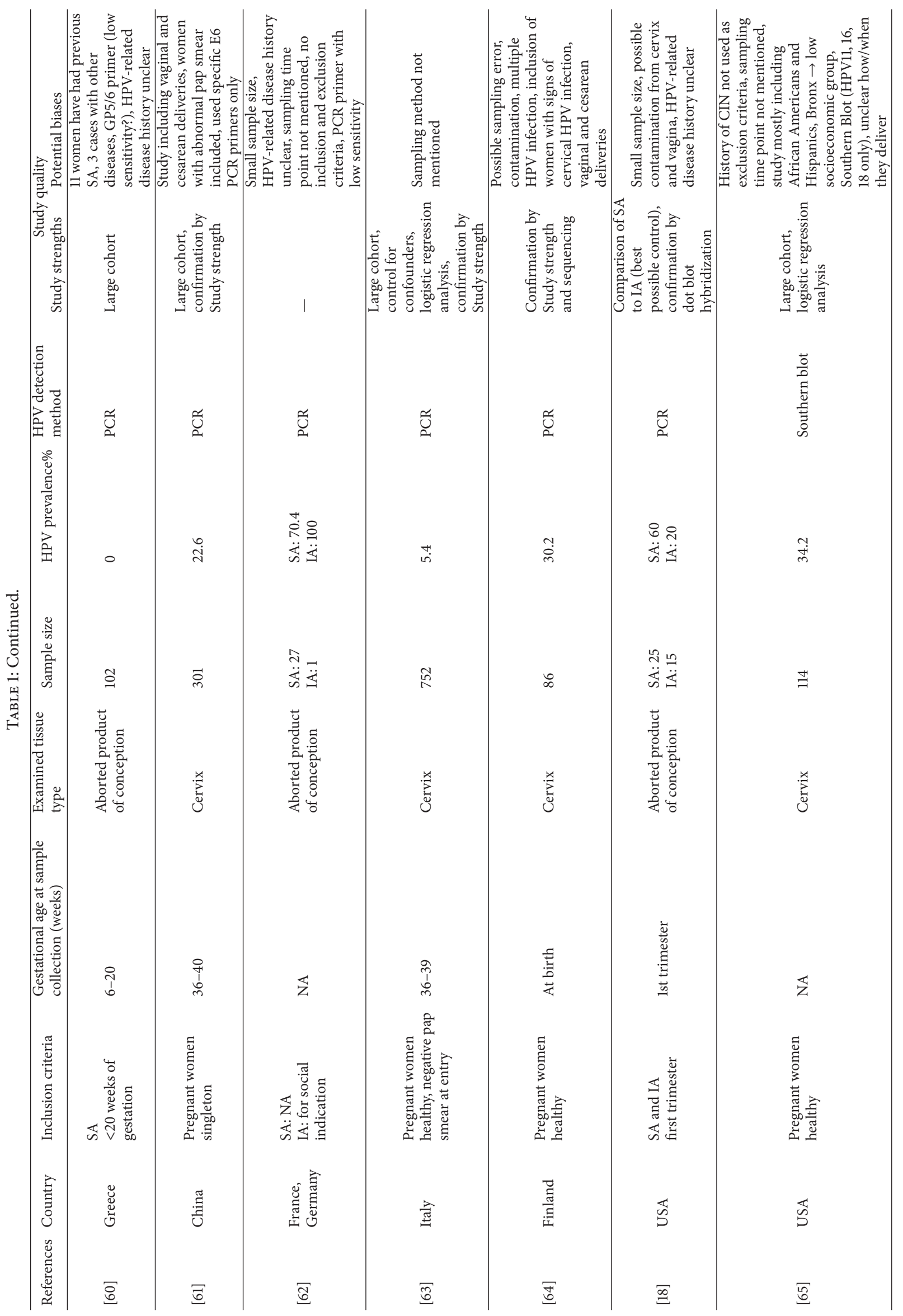




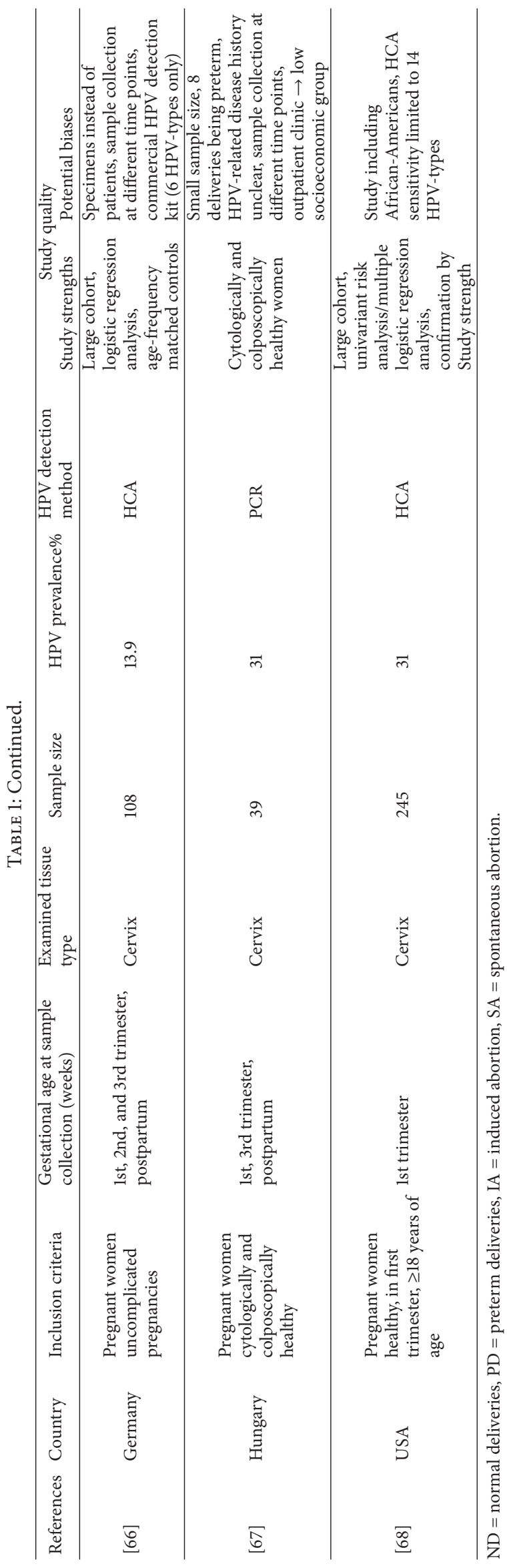




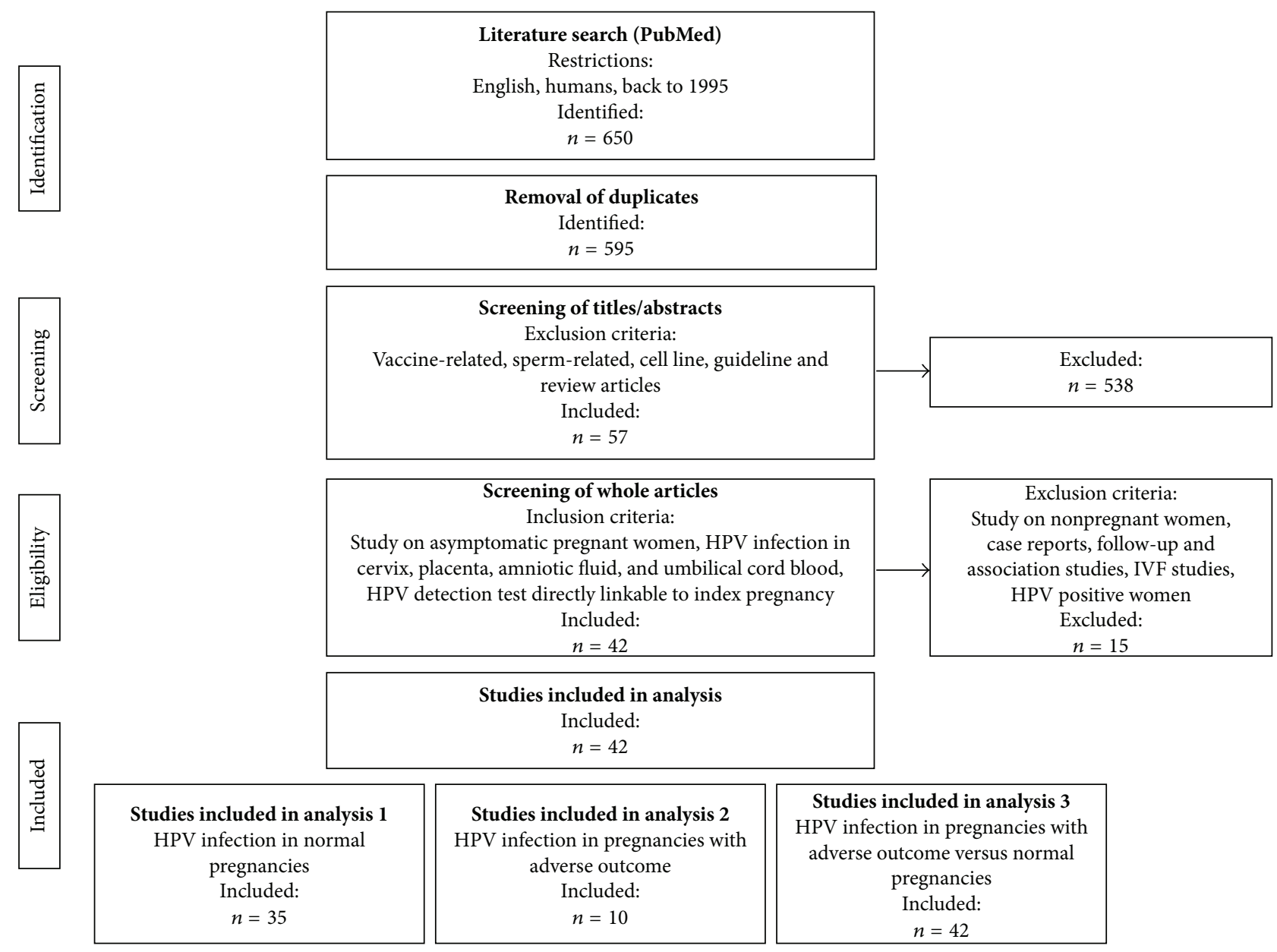

Figure 1: Flow diagram of literature search. The flow diagram shows the search in the PubMed database. A supplementary search in the Embase database was conducted in the same way and resulted in three additional articles for data extraction and quantitative analysis.

$32,38,40,42,43,45,47,51,58-60,62-64,66,67]$, Asia $(n=7116)[23,34,35,37,39,41,46,52,55,57,61]$, USA $(n=1681)[18,20,21,29,48,53,56,65,68]$, and Latin America $(n=1034)[36,44,49,50,54]$. Table 1 shows demographic characteristics, key aspects of study design, and study strength and potential biases of all included studies.

3.2. HPV Prevalence in Different Tissue Types of Normal Full-Term Pregnancies. HPV prevalence in healthy pregnant women giving birth at term was investigated in 38 of the 45 included studies and provided data on 13757 pregnant women. HPV prevalence appears to be highly dependent on the tissue type tested (Figure 2). In all studies included, HPV prevalence varied between $2.2 \%$ and $75 \%$ in cervical tissue, with a summary estimate of $17.5 \%$ (95\% CI; 17.3-17.7). In placental tissue and abortion products, $8.3 \%$ (95\% CI; 7.6-9.1) of the analyzed pregnancies were found to be HPV positive and varied between $0 \%$ and $47.2 \%$. HPV prevalence in amniotic fluid varied between $0 \%$ and $25 \%$, with a summary estimate of 5.7\% (95\% CI; 5.1-6.3). Finally, umbilical cord blood was calculated to be HPV positive in $10.9 \%$ (95\% CI; 10.1-11.7) of all cases and varied between $0 \%$ and $57.9 \%$. The difference between all proportions was significant $(P<0.05$, $P<0.001$, and $P<0.0001$, resp.).

3.3. HPV Prevalence in Pregnancies with Adverse Outcome and Comparison to Normal Pregnancies. HPV prevalence in pregnancies with adverse outcome, including spontaneous abortion and spontaneous preterm delivery, was investigated in 10 of the 45 included studies and provided data on 681 pregnancies. Three studies were investigating cervical HPV infection and seven studies looking at HPV prevalence in placental tissue. Details are given in Table 2. Only one study analyzed HPV prevalence in cervical tissue of spontaneous abortions and found $24.5 \%$ of all cervical samples to be HPV positive (Table 2). Placental HPV prevalence in spontaneous abortions varied between $0 \%$ and $70.4 \%$, with a summary estimate of $24.9 \%$ (95\% CI; 22.4-27.5) (Table 2). HPV prevalence in spontaneous preterm deliveries was found to be $47 \%$ (95\% CI; 42.3-51.6) in cervix, with a variation between $15.6 \%$ and $67.1 \%$ (Table 2). Placental tissue of spontaneous preterm deliveries was only investigated in one study where a HPV prevalence of $50 \%$ was observed (Table 2).

The overall HPV prevalence in cervical tissue of normal pregnancies was found to be $17.5 \%$ (95\% CI; 17.3-17.7) 


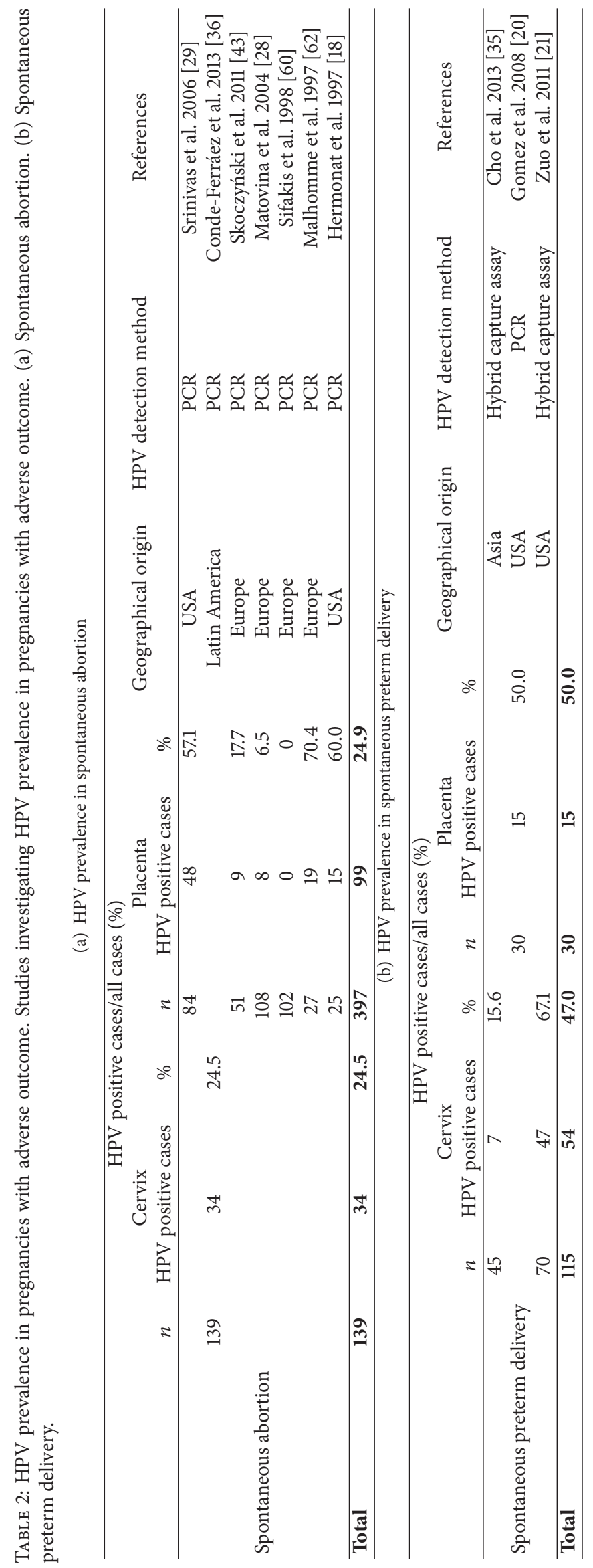




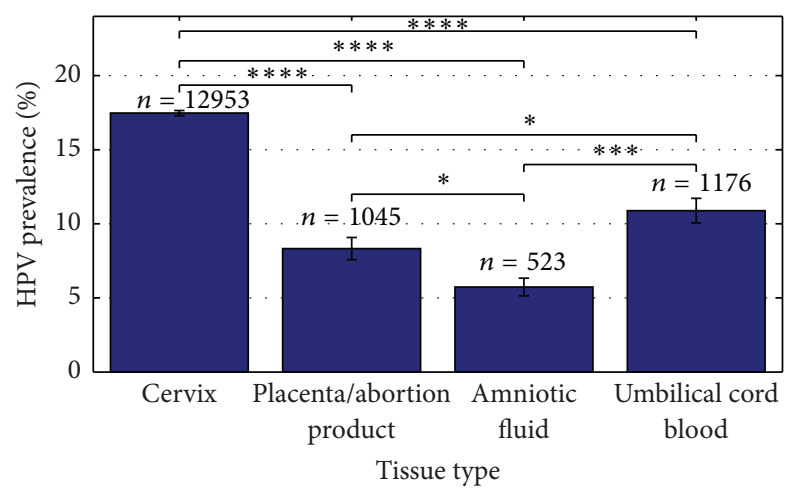

FIGURE 2: HPV prevalence depends on the investigated tissue type. HPV prevalence in different tissue types of normal pregnancies in $\%$. 38 studies have been included in the present analysis, $N_{\text {cervix }}=32$, $N_{\text {placenta/abortion product }}=9, N_{\text {amniotic fluid }}=4$, and $N_{\text {umbilical cord blood }}=$ 7. $N$ indicates number of studies included. $n$ indicates number of cases included. ${ }^{*} P<0.05,{ }^{* * *} P<0.001$, and ${ }^{* * * *} P<0.0001$.

(Figure 2). This is significantly lower than in spontaneous preterm deliveries $(47 \%, P<0.0001)$ and spontaneous abortions $(24.5 \%, P<0.05)$ (Figure 3$)$. An even bigger contrasting picture is seen in placental tissue. Here normal pregnancies are found to be HPV positive in 8.3\% (95\% CI; 7.6-9.1) of all cases (Figure 2), whereas placental tissues of spontaneous preterm deliveries and spontaneous abortions are found to be positive in $50 \%(P<0.0001)$ and $24.9 \%(P<0.0001)$ of cases, respectively (Figure 3 ).

3.4. HPV Prevalence in Normal Pregnancies Depends on Geographical Location. Information on geographical distribution of the investigated studies was collected to see if ethnicity might be a contributing factor to the great variation in HPV prevalence observed. The goal of the investigation was to determine whether women from different countries may be differentially exposed to HPV and some may thereby have a higher risk for possible HPV-induced pregnancy deficiencies.

Figure 4 shows the geographical distribution of HPV prevalence in cervical specimens from women with normal full-term pregnancies. Here it is clear that pregnant women from USA and Latin America have a significantly higher $(P<$ 0.0001) HPV prevalence compared to European and Asian women (Figure 4). Latin America is represented by Mexico and Brazil and the summary estimate for HPV prevalence was $35.5 \%$ (95\% CI; 34.6-36.5). HPV prevalence found in the included studies varied between $15.2 \%$ and $75 \%$. The analysis of the population from USA found a HPV prevalence of $29.6 \%$ (95\% CI; 29.5-29.7). Here a variation of $28 \%$ to $34.2 \%$ has been reported. The Asian population is represented by China, Japan, and Korea. The cervical HPV prevalence in Asia varied between $10.1 \%$ and $36.2 \%$, with a summary estimate of $16.4 \%$ (95\% CI; 16.3-16.6). The European population is represented by Spain, France, Italy, Germany, Belgium, Netherlands, Finland, Switzerland, Austria, Hungary, Greece, Croatia, Turkey, Poland, and Lithuania and the HPV prevalence varied between $2.2 \%$ and $36.6 \%$, with a summary estimate of $11 \%$ (95\% CI; 10.7-11.3). The difference between all proportions was highly significant $(P<0.01$ and $P<0.0001$, resp.), meaning that HPV prevalence in pregnant women is dependent on geographical or ethnical parameters, with pregnant women from USA and Latin America having the highest HPV prevalence reported. The same tendency can be observed in placenta, amniotic fluid, and umbilical cord blood, but numbers were insufficient for proper analyses.

Variation of HPV prevalence between studies conducted on different continents can also be observed in studies investigating pregnancies with adverse outcome (Table 2), but a proper analysis is difficult due to the small number of studies. However, it can be stated that studies from USA consistently report a significantly higher HPV prevalence in spontaneous abortions and spontaneous preterm deliveries compared to normal pregnancies, in both cervical and placental tissue [18, $20,21,29]$. European studies vary a lot in their HPV prevalence found in placenta, which makes it difficult to estimate the risk of a HPV infection for European pregnant women. There are no studies conducted on cervical specimens of spontaneous abortions or spontaneous preterm deliveries in Europe. Asian and Latin American studies are also limited $[35,36]$ and a conclusion of the risk of HPV infection for pregnant women is not possible. It can though be speculated whether the relatively high HPV prevalence found in the Latin American population of normal pregnancies (Figure 4) may influence the pregnancy outcome in those countries.

\subsection{Influence of the Time Point of Sample Collection and} the HPV Detection Method on HPV Prevalence. There are multiple factors that may influence HPV prevalence. For the present analysis, data on the time point of sample collection and the HPV detection methods used were collected. Figure 5(a) shows cervical HPV prevalence in relation to the time point of sample collection. Samples from the first trimester of pregnancy were found to be HPV positive in 23.9\% (95\% CI; 23.4-24.4) of all cases and showed a variation between $1.1 \%$ and $41.2 \%$. Samples taken at birth were tested positive in $21.7 \%$ (95\% CI; 21.3-22.2) of all cases. Here HPV prevalence varied between $12.6 \%$ and $30.2 \%$. The second and third trimester as well as postpartum samples showed a HPV prevalence of $16.7 \%$ (95\% CI; 16.5-17.0), 15.2\% (95\% CI; 14.915.6), and 17.3\% (95\% CI; 16.7-17.9). HPV prevalence varied between $2.2 \%$ and $40 \%, 5.2 \%$ and $75 \%$, and $6.2 \%$ and $27 \%$. The difference between proportions was significant $(P<0.05, P<$ $0.01, P<0.001$, and $P<0.0001$ resp.). Not significant was the difference between the proportions for the first trimester and at birth samples $(P=0.12)$, the second trimester and the third trimester, respectively, and the postpartum period $(P=0.07$ and $P=0.39$ ), and the third trimester and the postpartum period $(P=0.14)$.

Also the HPV detection methods used may influence the found HPV prevalence. Figure 5(b) shows the analysis of HPV prevalence according to the HPV detection method used. Hybrid capture assay identified HPV in 26.4\% (95\% CI; 25.6-27.2) of all analyzed samples. The HPV prevalence found varied between $0 \%$ and $67.1 \%$. The summary estimate for HPV prevalence by PCR was calculated to be $15.5 \%$ (95\% CI; $15.3-15.8$ ) and varied between studies from $0 \%$ to $100 \%$. 


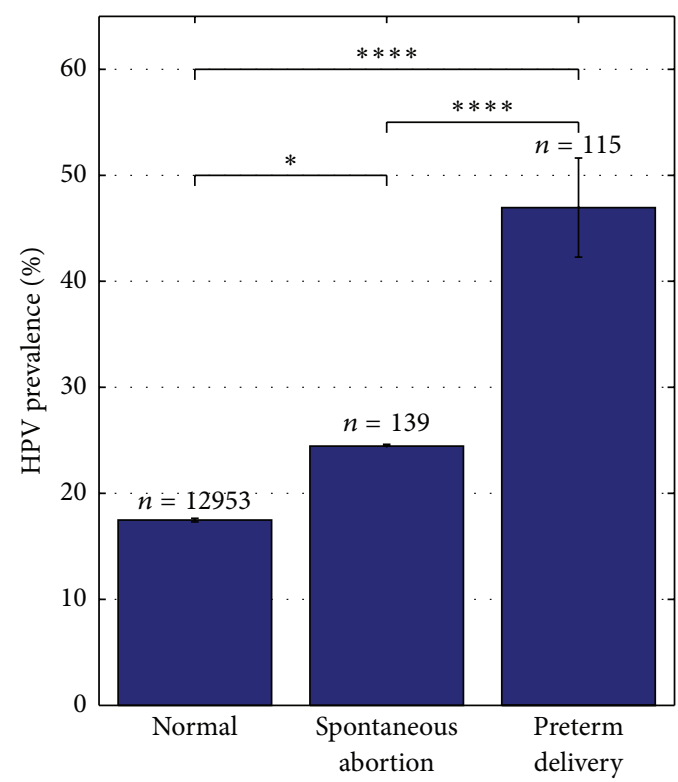

(a) Cervix

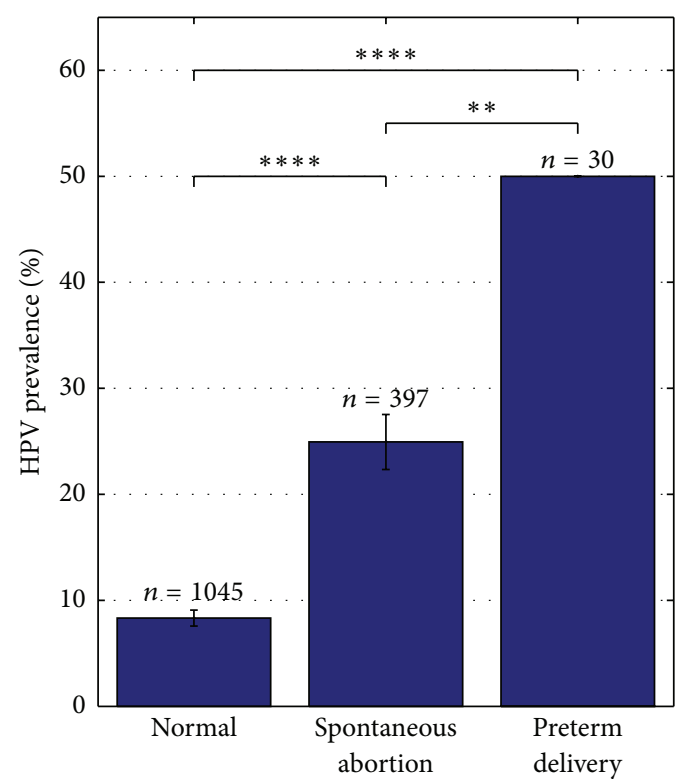

(b) Placenta

FIGURE 3: Higher HPV prevalence detected in pregnancies with adverse outcome compared to normal pregnancies. HPV prevalence in normal pregnancies, spontaneous abortions, and spontaneous preterm deliveries in \%. (a) In cervix. 34 studies have been included in the present analysis, $N_{\text {Normal }}=32, N_{\text {Spontaneous abortion }}=1$, and $N_{\text {Preterm delivery }}=2$. (b) In placenta. 14 studies have been included in the present analysis, $N_{\text {Normal }}=9, N_{\text {Spontaneous abortion }}=6$, and $N_{\text {Preterm delivery }}=1 . N$ indicated number of studies included. $n$ indicates number of cases included. ${ }^{*} P<0.05,{ }^{* *} P<0.01$, and ${ }^{* * * *} P<0.0001$.

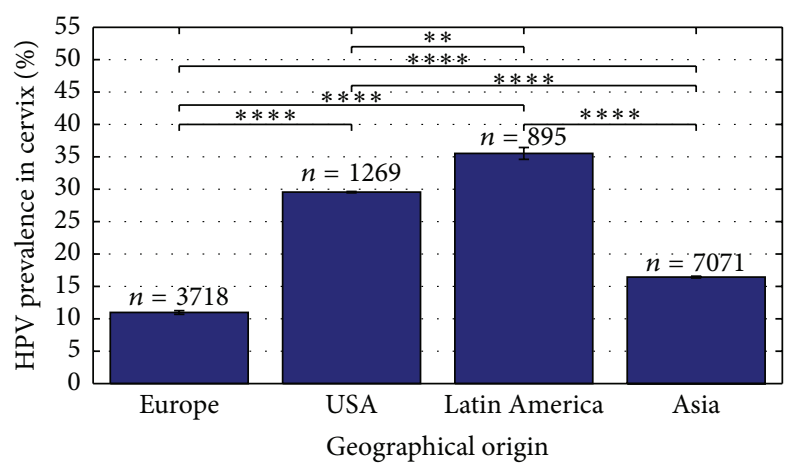

FIGURE 4: HPV prevalence in normal pregnancies depends on geographical location. HPV prevalence in cervix of normal pregnancies in \%. 32 studies have been included in the present analysis, $N_{\text {Europe }}=$ 13, $N_{\text {USA }}=4, N_{\text {Latin America }}=5$, and $N_{\text {Asia }}=10 . N$ indicated number of studies included. $n$ indicates number of cases included. ${ }^{* *} P<0.01,{ }^{* * * *} P<0.0001$.

HPV prevalence identified by DNA chip varied between $0 \%$ and $24.3 \%$, with a summary estimate of $15.1 \%$ (95\% CI; $15.0-$ 15.3). Southern blotting was only used in two studies and a HPV prevalence of 19.9\% (95\% CI; 18.7-21.0) has been found. HPV positivity varied between studies from $12 \%$ to $34.2 \%$. The difference between all but one of the proportions was significant $(P<0.05, P<0.01$, and $P<0.0001$, resp. $)$. Not significant was the difference between proportions for PCR and DNA chip $(P=0.25)$. The HPV detection method used most widely was PCR with $n=9674$ followed by DNA chip with $n=5461$.

\section{Discussion}

In this quantitative analysis on the prevalence of HPV infection in normal pregnancies and pregnancies with adverse outcome, 45 studies were included and data on 14470 pregnant women were analyzed and summarized. HPV prevalence in normal pregnancies was found to vary between tissue types and study populations of different geographical locations. The highest HPV prevalence could be reported in cervix (17.5\%; 95\% CI; 17.3-17.7) and in the population from Latin America (35.5\% (95\% CI; 34.6-36.5)) and USA (29.6\% (95\% CI; 29.5-29.7)). In comparison to HPV prevalence found in normal pregnancies, spontaneous abortions and spontaneous preterm deliveries were found to have higher HPV positive detection rates $(P<0.05$ and $P<0.0001)$, in both placenta (spontaneous abortions: $24.9 \%$, and preterm deliveries: $50 \%$ versus $8.3 \%$, resp.) and cervix (spontaneous abortions: $24.5 \%$, and preterm deliveries: $47 \%$ versus $17.5 \%$, resp.). Beyond the geographical location, the time point of sample collection in pregnancy as well as the HPV detection methods used may influence the results on HPV prevalence.

The present work has some weaknesses. First, heterogeneity between studies is a problem. Due to the limited number of studies conducted within the field of HPV infections and adverse pregnancy outcomes, inclusion criteria were set relatively widely. This results in a higher number of pregnancies to analyze but possibly more heterogeneous study groups and thereby inflict restricted options to compare directly between studies. The possibility of forming totally homogenous study groups is limited by the study quality and information given, 


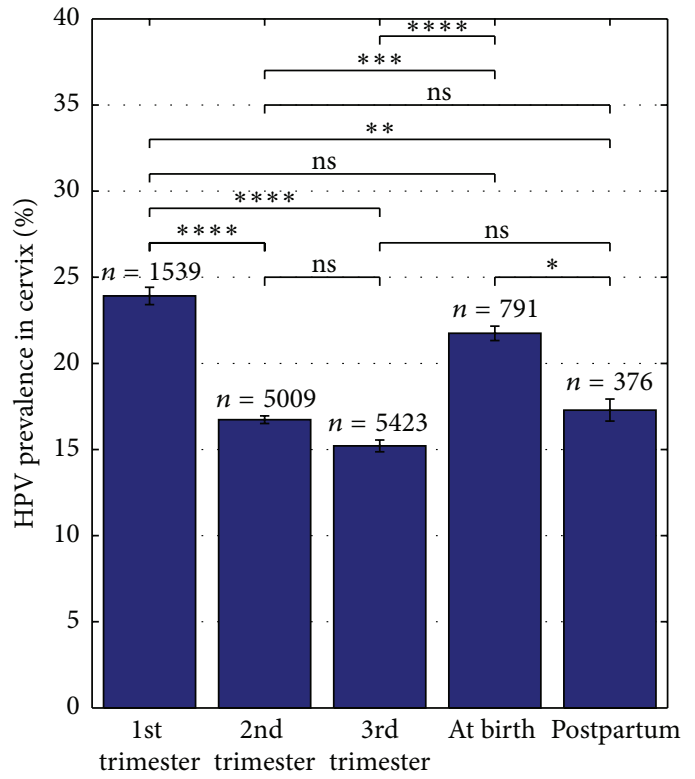

(a) Time of sample collection

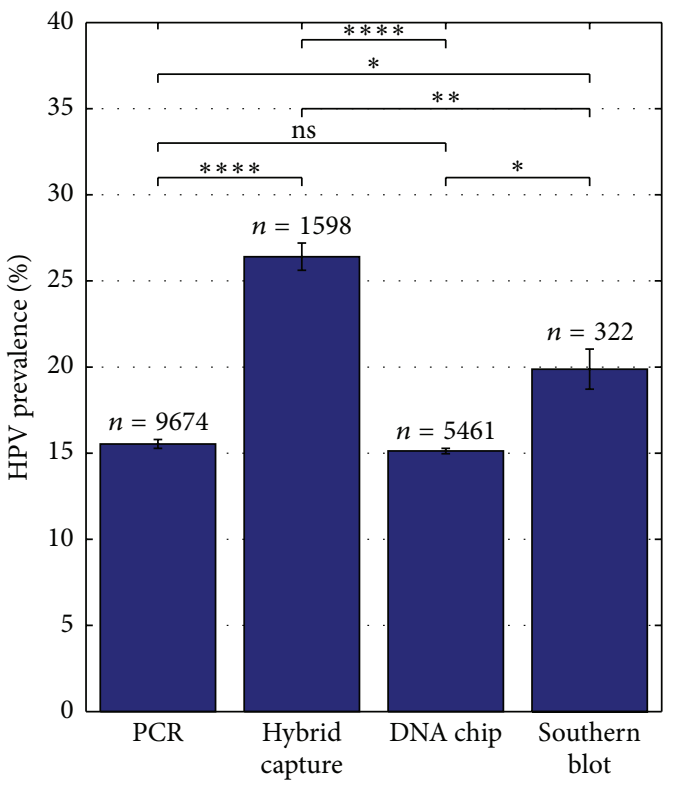

(b) Applied detection method

FIGURE 5: HPV prevalence depends on time of sample collection and on the applied HPV detection method. (a) Cervical HPV prevalence in $\%$ at different time points of sample collection of normal pregnancies. 25 studies have been included in the present analysis, $N_{1 \mathrm{st}}$ trimester $=10$, $N_{\text {nd trimester }}=10, N_{3 \mathrm{rd} \text { trimester }}=18, N_{\text {at birth }}=4$, and $N_{\text {postpartum }}=4$. (b) HPV prevalence in $\%$ in relation to the detection method used. Note that only two studies were using Southern blot as their main detection method. 45 studies have been included in the present analysis, $N_{\text {PCR }}=34, N_{\text {hybrid capture }}=8, N_{\text {DNA chip }}=5$, and $N_{\text {Southern blot }}=2 . N$ indicated number of studies included. $n$ indicates number of cases included. ${ }^{*} P<0.05,{ }^{* *} P<0.01,{ }^{* * *} P<0.001$, and ${ }^{* * * *} P<0.0001$; ns: not significant.

and data on patient-level is missing in most, if not all, of the included studies, which makes controlling for all potential biases difficult. Table 1 contains potential biases and study strength for every single study. Potential biases may include some of the following: unclear inclusion and exclusion criteria for participating women, missing information on ethnicity/method of sample collection/time point of sample collection/mode of delivery, study on highly selected group of women (cesarean sections, amniocentesis, and CVS) or group from low socioeconomically regions, and so forth. The interconnection between HPV infection and pregnancy outcome is complex and will therefore most probably not be explainable by a single parameter analyzed in the present work. The analyses done can however point towards a possible explanation by pregnancy outcome, geographical location, or HPV detection method. Second, studies vary in their inclusion of women with histories of HPV-related diseases. Approximately one-third excludes women with HPV-related lesions, whereas one-third does not exclude but report it and in the last third of studies this information is missing. Genital warts and cervical lesions are known to be HPV-related and a higher percentage of HPV infection would be expected. Third, studies of adverse pregnancies were few. The actual HPV prevalence may therefore be higher or lower than the ones reported in this paper. On the other hand, the present quantitative analysis includes over 14000 pregnancies and covers many different factors possibly influencing HPV prevalence, thereby providing a broad overview. Fourth, only studies published in English were included, which might limit the results. However, English is the primary common scientific language and the selection criterion "publications in English" is therefore considered to be acceptable.

HPV prevalence in pregnant women has been reported to be higher compared to nonpregnant women $[54,68,69]$. Our analysis of normal pregnancies, including 38 studies from 19 different countries on four continents, yields an overall HPV prevalence in the cervix for pregnant women of 17.5\% (95\% CI: 17.3-17.7). A worldwide meta-analysis by de Sanjosé et al. from 2007 reported a prevalence of cervical HPV infections in nonpregnant women with normal cytology of $10.4 \%$ [70]. The difference between the proportions is noticeable and it can therefore be speculated if a higher HPV prevalence in pregnant women can lead to various pregnancy complications. Pregnancy has previously been described as a state of immune suppression, facilitating the survival of the "semiallogeneic" fetus [52]. The inhibition of the host immune response may simultaneously increase the susceptibility to HPV and make it more difficult to clear HPV infections [54, 69, 71-74]. Higher incidences of HPV infection during pregnancy may though possibly be explained by the presence of hormone response elements in the HPV gene that could be triggered through high steroid levels [13, 14].

An infection with HPV during pregnancy has been associated with risk for spontaneous abortion and spontaneous preterm delivery as well as placental abnormalities [16-21]. Our analysis of 10 studies investigating HPV infection in pregnancies with adverse outcome found HPV prevalence in cervix and placenta to be higher than in normal full-term 
pregnancies, supporting the hypothesis of HPV infection being a risk for pregnancy outcome. Typically the placenta is a relatively effective barrier guarding against many microbes $[75,76]$ and the fetus in utero is therefore well protected. Nevertheless, multiple studies indicate that viral infection can impair trophoblast function, potentially contributing to pregnancy loss or abnormal implantation [76, 77]. Furthermore, upper genital tract infection was found to be an important cause of preterm birth [78].

As previously mentioned, the wide range of HPV prevalence found is related to several factors including study design, geographic and demographic characteristics, choice of detection method, and risk factor profiles, such as maternal age, gestational age, and history of cesarean section [31, $35,70,79]$. The present work underlines the importance to consider geographical and demographic variances. The HPV prevalence around the world was found to differ significantly (11-35.5\%) with Latin America having the highest cervical HPV prevalence in pregnant women. This is well in line with the previous literature where Latin America and Africa are reported as the geographical areas with the highest cervix cancer rate in the world [8]. North American studies do in general report a relatively high HPV prevalence $[20,48,56$, $65,68]$ and our analysis found a HPV prevalence of $29.6 \%$ (95\% CI; 29.5-29.7) for USA. This may be a bit puzzling since the population in North America due to historical reasons is expected to resemble the population in Europe. It can therefore be speculated that studies conducted in North America include a distinct number of the Latin American and African American population as has been stated by Gomez et al. in 2008 [20]. Unfortunately information of ethnicity of participating women is not available for many of the included studies, providing a potential bias to the results presented on geographical origin.

The time point of sample collection during pregnancy is thought to have an influence on HPV prevalence as differences in HPV prevalence regarding the trimester tested have been published [80-83]. Our analysis involved over 13000 samples and summarized many of the studies investigating the topic. Hereby the first trimester was found to have the highest overall HPV prevalence, closely followed by the samples taken at birth. Analyzed samples collected in the second and third trimester as well as in the postpartum period showed lower HPV prevalence. This is contradictory to studies reporting highest HPV prevalence during the second [34] and third [54, 65, 68] trimester. On the other hand, multiple HPV infections were observed in the first trimester by Yamasaki et al. in 2011 and high-risk HPV-types were found to be selectively increased in the first trimester as well $[46,68]$. It is however important to keep in mind that all those time points in reality are time intervals, thereby making a comparison very difficult. To reduce potential bias due to uncertainty about the time point of sample collection, we have chosen to include only studies providing information on the time point of sample collection. This is the case for 25 of the 45 included studies.

Finally, we compared HPV prevalence with respect to choice of HPV detection methods, since studies have shown that HPV DNA detectable and the HPV-genotypes identified largely depend on this [42]. Our analysis of HPV prevalence in regard to the applied detection methods revealed hybrid capture assay as the method detecting most HPV positive cases (Figure 5(b)). PCR is thought to be the most sensitive method, detecting less than 10 copies of HPV DNA $[46,84,85]$. In our analysis the HPV prevalence detected by PCR was found to be $15.5 \%$ (95\% CI; 15.3-15.8). Currently an increasing number of studies use broad spectrum primers $[26,31,56]$ instead of type-specific primers. These are designed to detect various HPV-types at the same time, hereby giving a broader picture of the HPV-types present. The downside of high sensitivities allowed by PCR is the risk of false-positives due to contamination [84]. It is therefore crucial to evaluate tissue samples on different molecular levels, confirming the detected virus to be correctly localized and active, thus being able to explain the causality of adverse pregnancy outcome or diseases in general.

Functional studies investigating HPV infection in relation to pregnancy are limited. Following the detection of HPV in placental tissue $[17,18,62]$ most research is focused on the study of HPV infections in trophoblast cell lines. Being one of the most critical tissues of the placenta, the trophoblast layer plays an important role in contacting maternal tissues and serves multiple roles during gestation. Several lines of evidence point towards the trophoblasts as being the target cells of placental HPV infection. First, it was shown that HPV is able to undergo a complete life cycle in trophoblast cell lines $[86,87]$. Second, trophoblast morphology and behavior during HPV infection have been investigated, reporting a higher rate of apoptosis and lower invasion capabilities, agreeing with possible placental dysfunction and adverse pregnancy outcome [20]. Third, studies analyzing trophoblast cells transfected with the HPV genes E5, E6, and E7 report effects on trophoblastic adhesion and increased migratory and invasive properties and may eventually explain potential abnormal implantation due to inappropriate trophoblast spreading [88]. However, a convincing role for HPV infection in connection with spontaneous abortion and spontaneous preterm delivery, at the molecular level, has still to be demonstrated.

\section{Conclusion}

Based on the present quantitative analyses it can be concluded that HPV prevalence is higher in pregnancies with adverse outcome, such as spontaneous abortion or spontaneous preterm delivery, compared to women experiencing a normal full-term pregnancy. HPV infection may therefore be constituted as a risk for the present pregnancy.

HPV prevalence has been shown to be dependent on the tissue type tested and the geographical location of the study population analyzed. However, the number of studies investigating HPV infection on material from spontaneous abortions and spontaneous preterm deliveries is very limited and study groups are heterogeneous which makes a reliable conclusion difficult. It can be stated that study design is important, the selection of proper controls is essential, and, for a valuable comparison between studies, similarity in samples/patients needs to be controlled as strictly as possible. Furthermore, one should keep in mind that the simple 
detection of a virus never is equal to a real causative role in the adverse outcome of a pregnancy or diseases in general. It is therefore inevitable to study the viral activity and cellular localization to be able to conclude on the impact for a given situation. Therefore we recommend including an investigation of the molecular mechanism of HPV infections in material of pregnancies with adverse outcome and inviting researchers to conduct new studies to clarify HPV's impact on spontaneous abortion and spontaneous preterm delivery. As a consequence of the aforementioned limitations our study group has initiated a prospective study addressing the complexity of HPV in pregnancy.

\section{Competing Interests}

The authors have no competing interests in connection with this paper. However, Jan Blaakær has received lecture fees and advisory board fees from Merck, Sanofi Pasteur MSD, and Glaxo Smith Kline.

\section{Acknowledgments}

The authors acknowledge Innovation Fund Denmark for the support of the present work. This work is financially supported by Center for Clinical Research, North Denmark Regional Hospital, and Department of Clinical Medicine, Aalborg University. Furthermore, the project has received funding of 180,000 DKK from "Region Nordjyllands Forskningsfond" and "Marie Pedersen og Jensine Heibergs Legat" to cover running expenses.

\section{References}

[1] G. G. Donders, B. Van Bulck, J. Caudron, L. Londers, A. Vereecken, and B. Spitz, "Relationship of bacterial vaginosis and mycoplasmas to the risk of spontaneous abortion," American Journal of Obstetrics \& Gynecology, vol. 183, no. 2, pp. 431-437, 2000.

[2] J. A. Robertson, L. H. Honore, and G. W. Stemke, "Serotypes of ureaplasma urealyticum in spontaneous abortion," Pediatric Infectious Disease Journal, vol. 5, no. 6, pp. S270-S272, 1986.

[3] M. G. Gravett, C. E. Rubens, and T. M. Nunes, "Global report on preterm birth and stillbirth (2 of 7): discovery science," BMC Pregnancy and Childbirth, vol. 10, supplement 1, p. S2, 2010.

[4] H.-U. Bernard, R. D. Burk, Z. Chen, K. van Doorslaer, H. Z. Hausen, and E.-M. de Villiers, "Classification of papillomaviruses (PVs) based on $189 \mathrm{PV}$ types and proposal of taxonomic amendments," Virology, vol. 401, no. 1, pp. 70-79, 2010.

[5] J. Doorbar, “The papillomavirus life cycle," Journal of Clinical Virology, vol. 32, supplement, pp. 7-15, 2005.

[6] M. A. Stanley, "Epithelial cell responses to infection with human papillomavirus," Clinical Microbiology Reviews, vol. 25, no. 2, pp. 215-222, 2012.

[7] P. Aggarwal, "Cervical cancer: can it be prevented?” World Journal of Clinical Oncology, vol. 5, no. 4, pp. 775-780, 2014.

[8] L. Bruni, L. Barrionuevo-Rosas, G. Albero et al., Human Papillomavirus and Related Diseases in the World. Summary Report 2014, 2014.

[9] H. A. Cubie, "Diseases associated with human papillomavirus infection," Virology, vol. 445, no. 1-2, pp. 21-34, 2013.
[10] E. D. Weinberg, "Pregnancy-associated depression of cell-mediated immunity," Reviews of Infectious Diseases, vol. 6, no. 6, pp. 814-831, 1984.

[11] G. Entrican, "Immune regulation during pregnancy and hostpathogen interactions in infectious abortion," Journal of Comparative Pathology, vol. 126, no. 2-3, pp. 79-94, 2002.

[12] H. Huddleston and D. J. Schust, "Immune interactions at the maternal-fetal interface: a focus on antigen presentation," American Journal of Reproductive Immunology, vol. 51, no. 4, pp. 283-289, 2004.

[13] C. Worda, A. Huber, G. Hudelist et al., "Prevalence of cervical and intrauterine human papillomavirus infected in the third trimester in asymptomatic women," Journal of the Society for Gynecologic Investigation, vol. 12, no. 6, pp. 440-444, 2005.

[14] R. Mittal, A. Pater, and M. M. Pater, "Multiple human papillomavirus type 16 glucocorticoid response elements functional for transformation, transient expression, and DNA-protein interactions," Journal of Virology, vol. 67, no. 9, pp. 5656-5659, 1993.

[15] P. Liu, L. Xu, Y. Sun, and Z. Wang, "The prevalence and risk of human papillomavirus infection in pregnant women," Epidemiology \& Infection, vol. 142, no. 8, pp. 1567-1578, 2014.

[16] C. C. Pao, J. J. Hor, C.-J. Wu, Y.-F. Shi, X. Xie, and S.-M. Lu, "Human papillomavirus type 18 DNA in gestational trophoblastic tissues and choriocarcinomas," International Journal of Cancer, vol. 63, no. 4, pp. 505-509, 1995.

[17] B. Sikstroöm, D. Hellberg, S. Nilsson, C. Brihmer, and P.-A. Mårdh, "Contraceptive use and reproductive history in women with cervical human papillomavirus infection," Advances in Contraception, vol. 11, no. 4, pp. 273-284, 1995.

[18] P. L. Hermonat, L. Han, P. J. Wendel et al., "Human papillomavirus is more prevalent in first trimester spontaneously aborted products of conception compared to elective specimens," Virus Genes, vol. 14, no. 1, pp. 13-17, 1997.

[19] M. Rabreau and J. Saurel, "Presence of human papilloma viruses in the deciduous membranes of early abortion products," $L a$ Presse medicale, vol. 26, p. 1724, 1997.

[20] L. M. Gomez, Y. Ma, C. Ho, C. M. McGrath, D. B. Nelson, and S. Parry, "Placental infection with human papillomavirus is associated with spontaneous preterm delivery," Human Reproduction, vol. 23, no. 3, pp. 709-715, 2008.

[21] Z. Zuo, S. Goel, and J. E. Carter, "Association of cervical cytology and HPV DNA status during pregnancy with placental abnormalities and preterm birth," American Journal of Clinical Pathology, vol. 136, no. 2, pp. 260-265, 2011.

[22] W. Eppel, C. Worda, P. Frigo, M. Ulm, E. Kucera, and K. Czerwenka, "Human papillomavirus in the cervix and placenta," Obstetrics and Gynecology, vol. 96, no. 3, pp. 337-341, 2000.

[23] H. S. Hahn, M. K. Kee, H. J. Kim et al., "Distribution of maternal and infant human papillomavirus: risk factors associated with vertical transmission," European Journal of Obstetrics Gynecology and Reproductive Biology, vol. 169, no. 2, pp. 202-206, 2013.

[24] X. Wang, Q. Zhu, and H. Rao, "Maternal-fetal transmission of human papillomavirus," Chinese Medical Journal, vol. 111, no. 8, pp. 726-727, 1998.

[25] E. Armbruster-Moraes, L. M. Ioshimoto, E. Leao, and M. Zugaib, "Detection of human papillomavirus deoxyribonucleic acid sequences in amniotic fluid during different periods of pregnancy," American Journal of Obstetrics and Gynecology, vol. 169, no. 4, pp. 1074-1075, 1993.

[26] R. L. Rombaldi, E. P. Serafini, J. Mandelli, E. Zimmermann, and K. P. Losquiavo, "Transplacental transmission of human papillomavirus," Virology Journal, vol. 5, article 106, 2008. 
[27] M. E. Sarkola, S. E. Grénman, M. A. M. Rintala, K. J. Syrjänen, and S. M. Syrjänen, "Human papillomavirus in the placenta and umbilical cord blood," Acta Obstetricia et Gynecologica Scandinavica, vol. 87, no. 11, pp. 1181-1188, 2008.

[28] M. Matovina, K. Husnjak, N. Milutin, S. Ciglar, and M. Grce, "Possible role of bacterial and viral infections in miscarriages," Fertility and Sterility, vol. 81, no. 3, pp. 662-669, 2004.

[29] S. K. Srinivas, Y. Ma, M. D. Sammel et al., "Placental inflammation and viral infection are implicated in second trimester pregnancy loss," American Journal of Obstetrics \& Gynecology, vol. 195, no. 3, pp. 797-802, 2006.

[30] E. M. Smith, J. M. Ritchie, J. Yankowitz et al., "Human papillomavirus prevalence and types in newborns and parents: concordance and modes of transmission," Sexually Transmitted Diseases, vol. 31, no. 1, pp. 57-62, 2004.

[31] L. R. Medeiros, A. B. de Moraes Ethur, J. B. Hilgert et al., "Vertical transmission of the human papillomavirus: a systematic quantitative review," Cadernos de Saúde Pública, vol. 21, no. 4, pp. 1006-1015, 2005.

[32] C. Weyn, D. Thomas, J. Jani et al., "Evidence of human papillomavirus in the placenta," Journal of Infectious Diseases, vol. 203, no. 3, pp. 341-343, 2011.

[33] D. Moher, A. Liberati, J. Tetzlaff, and D. G. Altman, "Preferred reporting items for systematic reviews and meta-analyses: the PRISMA statement," BMJ, vol. 339, no. 7716, pp. 332-336, 2009.

[34] Y. H. Kim, J. S. Park, E. R. Norwitz et al., "Genotypic prevalence of human papillomavirus infection during normal pregnancy: a cross-sectional study," Journal of Obstetrics and Gynaecology Research, vol. 40, no. 1, pp. 200-207, 2014.

[35] G. Cho, K.-J. Min, H.-R. Hong et al., "High-risk human papillomavirus infection is associated with premature rupture of membranes," BMC Pregnancy and Childbirth, vol. 13, article 173, 2013.

[36] L. Conde-Ferráez, A. D. A. Chan May, J. R. Carrillo-Martínez, G. Ayora-Talavera, and M. D. R. González-Losa, "Human papillomavirus infection and spontaneous abortion: a case-control study performed in Mexico," European Journal of Obstetrics Gynecology and Reproductive Biology, vol. 170, no. 2, pp. 468473, 2013.

[37] S. M. Lee, J. S. Park, E. R. Norwitz et al., "Risk of vertical transmission of human papillomavirus throughout pregnancy: a prospective study," PLoS ONE, vol. 8, no. 6, Article ID e66368, 2013.

[38] M. Skoczyński, A. Goździcka-Józefiak, and A. Kwaśniewska, "Risk factors of the vertical transmission of human papilloma virus in newborns from singleton pregnancy-preliminary report," Journal of Maternal-Fetal \& Neonatal Medicine, vol. 27, no. 3, pp. 239-242, 2014.

[39] Y. Hong, S.-Q. Li, Y.-L. Hu, and Z.-Q. Wang, "Survey of human papillomavirus types and their vertical transmission in pregnant women," BMC Infectious Diseases, vol. 13, no. 1, article 109, 2013.

[40] C. E. Schmeink, W. J. G. Melchers, J. C. M. Hendriks, W. G. V. Quint, L. F. Massuger, and R. L. M. Bekkers, "Human papillomavirus detection in pregnant women: a prospective matched cohort study," Journal of Women's Health, vol. 21, no. 12, pp. 1295-1301, 2012.

[41] H. Park, S. W. Lee, I. H. Lee et al., "Rate of vertical transmission of human papillomavirus from mothers to infants: relationship between infection rate and mode of delivery," Virology Journal, vol. 9, article 80, 2012.

[42] H.-M. Koskimaa, T. Waterboer, M. Pawlita, S. Grénman, K. Syrjänen, and S. Syrjänen, "Human papillomavirus genotypes present in the oral mucosa of newborns and their concordance with maternal cervical human papillomavirus genotypes," Journal of Pediatrics, vol. 160, no. 5, pp. 837-843, 2012.

[43] M. Skoczyński, A. Goździcka-Józefiak, and A. Kwaśniewska, "Prevalence of human papillomavirus in spontaneously aborted products of conception," Acta Obstetricia et Gynecologica Scandinavica, vol. 90, no. 12, pp. 1402-1405, 2011.

[44] O. Uribarren-Berrueta, J. Sánchez-Corona, H. MontoyaFuentes, B. Trujillo-Hernández, and C. Vásquez, "Presence of HPV DNA in placenta and cervix of pregnant Mexican women," Archives of Gynecology and Obstetrics, vol. 285, no. 1, pp. 55-60, 2012.

[45] G. Domža, Ž. Gudlevičienė, J. Didžiapetrienè, K. P. Valuckas, B. Kazbariene, and G. Drąsutienè, "Human papillomavirus infection in pregnant women," Archives of Gynecology and Obstetrics, vol. 284, no. 5, pp. 1105-1112, 2011.

[46] K. Yamasaki, K. Miura, T. Shimada et al., "Epidemiology of human papillomavirus genotypes in pregnant Japanese women," Journal of Human Genetics, vol. 56, no. 4, pp. 313-315, 2011.

[47] B. Dinc, G. Bozdayi, A. Biri et al., "Molecular detection of cytomegalovirus, herpes simplex virus 2, human papillomavirus 16-18 in Turkish pregnants," Brazilian Journal of Infectious Diseases, vol. 14, no. 6, pp. 569-574, 2010.

[48] E. M. Smith, M. A. Parker, L. M. Rubenstein, T. H. Haugen, E. Hamsikova, and L. P. Turek, "Evidence for vertical transmission of HPV from mothers to infants," Infectious Diseases in Obstetrics and Gynecology, vol. 2010, Article ID 326369, 7 pages, 2010.

[49] S. M. M. Pereira, D. Etlinger, L. S. Aguiar, S. V. Peres, and A. Longatto Filho, "Simultaneous Chlamydia trachomatis and HPV infection in pregnant women," Diagnostic Cytopathology, vol. 38, no. 6, pp. 397-401, 2010.

[50] L. B. Freitas, C. C. Pereira, R. Checon, J. P. G. Leite, J. P. Nascimento, and L. C. Spano, "Adeno-associated virus and human papillomavirus types in cervical samples of pregnant and non-pregnant women," European Journal of Obstetrics Gynecology and Reproductive Biology, vol. 145, no. 1, pp. 41-44, 2009.

[51] X. Castellsagué, T. Drudis, M. P. Cañadas et al., "Human Papillomavirus (HPV) infection in pregnant women and motherto-child transmission of genital HPV genotypes: a prospective study in Spain," BMC Infectious Diseases, vol. 9, article 74, 2009.

[52] K. Takakuwa, T. Mitsui, M. Iwashita et al., "Studies on the prevalence of human papillomavirus in pregnant women in Japan," Journal of Perinatal Medicine, vol. 34, no. 1, pp. 77-79, 2006.

[53] M. T. Ruffin IV, J. M. Bailey, D. Roulston et al., "Human papillomavirus in amniotic fluid," BMC Pregnancy and Childbirth, vol. 6, article 28, 2006.

[54] C. Hernández-Girón, J. S. Smith, A. Lorincz, E. Lazcano, M. Hernández-Ávila, and J. Salmerón, "High-risk human papillomavirus detection and related risk factors among pregnant and nonpregnant women in Mexico," Sexually Transmitted Diseases, vol. 32, no. 10, pp. 613-618, 2005.

[55] D. Deng, L. Wen, W. Chen, and X. Ling, "Asymptomatic genital infection of human papillomavirus in pregnant women and the vertical transmission route," Journal of Huazhong University of Science and Technology, vol. 25, no. 3, pp. 343-345, 2005.

[56] E. M. Smith, J. M. Ritchie, J. Yankowitz, D. Wang, L. P. Turek, and T. H. Haugen, "HPV prevalence and concordance in the cervix and oral cavity of pregnant women," Infectious Disease in Obstetrics and Gynecology, vol. 12, no. 2, pp. 45-56, 2004. 
[57] P. K. S. Chan, A. R. Chang, W.-H. Tam, J. L. K. Cheung, and A. F. Cheng, "Prevalence and genotype distribution of cervical human papillomavirus infection: comparison between pregnant women and non-pregnant controls," Journal of Medical Virology, vol. 67, no. 4, pp. 583-588, 2002.

[58] T. Burguete, M. Rabreau, M. Fontanges-Darriet et al., "Evidence for infection of the human embryo with adeno-associated virus in pregnancy," Human Reproduction, vol. 14, no. 9, pp. 23962401, 1999.

[59] P. Tenti, R. Zappatore, P. Migliora, A. Spinillo, C. Belloni, and L. Carnevali, "Perinatal transmission of human papillomavirus from gravidas with latent infections," Obstetrics and Gynecology, vol. 93, no. 4, pp. 475-479, 1999.

[60] S. Sifakis, M. Ergazaki, G. Sourvinos, M. Koffa, E. Koumantakis, and D. A. Spandidos, "Evaluation of Parvo B19, CMV and HPV viruses in human aborted material using the polymerase chain reaction technique," European Journal of Obstetrics Gynecology and Reproductive Biology, vol. 76, no. 2, pp. 169-173, 1998.

[61] C.-J. Tseng, C.-C. Liang, Y.-K. Soong, and C.-C. Pao, "Perinatal transmission of human papillomavirus in infants: relationship between infection rate and mode of delivery," Obstetrics and Gynecology, vol. 91, no. 1, pp. 92-96, 1998.

[62] O. Malhomme, N. Dutheil, M. Rabreau, E. Armbruster-Moraes, J. R. Schlehofer, and T. Dupressoir, "Human genital tissues containing DNA of adeno-associated virus lack DNA sequences of the helper viruses adenovirus, herpes simplex virus or cytomegalovirus but frequently contain human papillomavirus DNA," Journal of General Virology, vol. 78, no. 8, pp. 1957-1962, 1997.

[63] P. Tenti, R. Zappatore, P. Migliora et al., "Latent human papillomavirus infection in pregnant women at term: a case- control study," Journal of Infectious Diseases, vol. 176, no. 1, pp. 277-280, 1997.

[64] M. H. Puranen, M. H. Yliskoski, S. V. Saarikoski, K. J. Syrjanen, and S. M. Syrjanen, "Exposure of an infant to cervical human papillomavirus infection of the mother is common," American Journal of Obstetrics and Gynecology, vol. 176, no. 5, pp. 10391045, 1997.

[65] E. A. B. Morrison, M. D. Gammon, G. L. Goldberg, S. H. Vermund, and R. D. Burk, "Pregnancy and cervical infection with human papillomaviruses," International Journal of Gynecology and Obstetrics, vol. 54, no. 2, pp. 125-130, 1996.

[66] J. Chang-Claude, A. Schneider, E. Smith, M. Blettner, J. Wahrendorf, and L. Turek, "Longitudinal study of the effects of pregnancy and other factors on detection of HPV," Gynecologic Oncology, vol. 60, no. 3, pp. 355-362, 1996.

[67] G. L. Veress, T. Csiky-Mészáros, J. Kónya, J. Czeglédy, and L. Gergely, "Follow-up of human papillomavirus (HPV) DNA and local anti-HPV antibodies in cytologically normal pregnant women," Medical Microbiology and Immunology, vol. 185, no. 3, pp. 139-144, 1996.

[68] K. H. Fife, B. P. Katz, J. Roush, V. D. Handy, D. R. Brown, and R. Hansell, "Cancer-associated human papillomavirus types are selectively increased in the cervix of women in the first trimester of pregnancy," American Journal of Obstetrics and Gynecology, vol. 174, no. 5, pp. 1487-1493, 1996.

[69] Y. Aydin, A. Atis, T. Tutuman, and N. Goker, "Prevalence of human papilloma virus infection in pregnant Turkish women compared with non-pregnant women," European Journal of Gynaecological Oncology, vol. 31, no. 1, pp. 72-74, 2010.
[70] S. de Sanjosé, M. Diaz, X. Castellsagué et al., "Worldwide prevalence and genotype distribution of cervical human papillomavirus DNA in women with normal cytology: a metaanalysis," Lancet Infectious Diseases, vol. 7, no. 7, pp. 453-459, 2007.

[71] K. Kelley and S. H. Vermund, "Human papillomavirus in women: methodologic issues and role of immunosuppression," in Reproductive and Perinatal Epidemiology, pp. 158-159, 1990.

[72] K. H. Fife, B. P. Katz, E. J. Brizendine, and D. R. Brown, "Cervical human papillomavirus deoxyribonucleic acid persists throughout pregnancy and decreases in the postpartum period," American Journal of Obstetrics and Gynecology, vol. 180, no. 5, pp. 1110-1114, 1999.

[73] S. Sethi, M. Muller, A. Schneider et al., "Serologic response to the E4, E6, and E7 proteins of human papillomavirus type 16 in pregnant women," American Journal of Obstetrics \& Gynecology, vol. 178, no. 2, pp. 360-364, 1998.

[74] M. A. E. Nobbenhuis, T. J. M. Helmerhorst, A. J. C. Van den Brule et al., "High-risk human papillomavirus clearance in pregnant women: trends for lower clearance during pregnancy with a catch-up postpartum," British Journal of Cancer, vol. 87, no. 1, pp. 75-80, 2002.

[75] A. Alanen, "Polymerase chain reaction in the detection of microbes in amniotic fluid," Annals of Medicine, vol. 30, no. 3, pp. 288-295, 1998.

[76] H. Koi, J. Zhang, and S. Parry, "The mechanisms of placental viral infection," Annals of the New York Academy of Sciences, vol. 943, pp. 148-156, 2001.

[77] F. Arechavaleta-Velasco, H. Koi, J. F. Strauss III, and S. Parry, "Viral infection of the trophoblast: time to take a serious look at its role in abnormal implantation and placentation?" Journal of Reproductive Immunology, vol. 55, no. 1-2, pp. 113-121, 2002.

[78] W. W. Andrews, R. L. Goldenberg, and J. C. Hauth, "Preterm labor: emerging role of genital tract infections," Infectious Agents and Disease, vol. 4, no. 4, pp. 196-211, 1995.

[79] S. Syrjänen and M. Puranen, "Human papillomavirus infections in children: the potential role of maternal transmission," Critical Reviews in Oral Biology and Medicine, vol. 11, no. 2, pp. 259-274, 2000.

[80] A. Schneider, M. Hotz, and L. Gissmann, "Increased prevalence of human papillomaviruses in the lower genital tract of pregnant women," International Journal of Cancer, vol. 40, no. 2, pp. 198-201, 1987.

[81] R. F. Rando, S. Lindheim, L. Hasty, T. V. Sedlacek, M. Woodland, and C. Eder, "Increased frequency of detection of human papillomavirus deoxyribonucleic acid in exfoliated cervical cells during pregnancy," American Journal of Obstetrics and Gynecology, vol. 161, no. 1, pp. 50-55, 1989.

[82] E. M. Smith, S. R. Johnson, D. Jiang et al., "The association between pregnancy and human papilloma virus prevalence," Cancer Detection and Prevention, vol. 15, no. 5, pp. 397-402, 1991.

[83] A. M. De Roda Husman, J. M. M. Walboomers, E. Hopman et al., "HPV prevalence in cytomorphologically normal cervical scrapes of pregnant women as determined by PCR: the agerelated pattern," Journal of Medical Virology, vol. 46, no. 2, pp. 97-102, 1995.

[84] T. Iftner and L. L. Villa, "Chapter 12: human papillomavirus technologies," Journal of the National Cancer Institute Monographs, vol. 2003, no. 31, pp. 80-88, 2003.

[85] P. J. F. Snijders, A. J. C. van den Brule, and C. J. L. M. Meijer, "The clinical relevance of human papillomavirus testing: 
relationship between analytical and clinical sensitivity," The Journal of Pathology, vol. 201, no. 1, pp. 1-6, 2003.

[86] Y. Liu, H. You, M. Chiriva-Internati et al., "Display of complete life cycle of human papillomavirus type 16 in cultured placental trophoblasts," Virology, vol. 290, no. 1, pp. 99-105, 2001.

[87] H. You, Y. Liu, N. Agrawal et al., "Infection, replication, and cytopathology of human papillomavirus type 31 in trophoblasts," Virology, vol. 316, no. 2, pp. 281-289, 2003.

[88] S. Boulenouar, C. Weyn, M. van Noppen et al., "Effects of HPV16 E5, E6 and E7 proteins on survival, adhesion, migration and invasion of trophoblastic cells," Carcinogenesis, vol. 31, no. 3, pp. 473-480, 2010. 


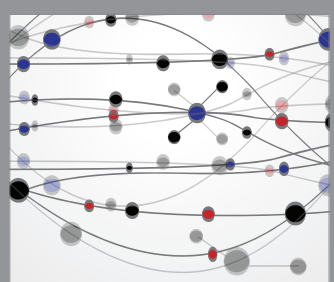

The Scientific World Journal
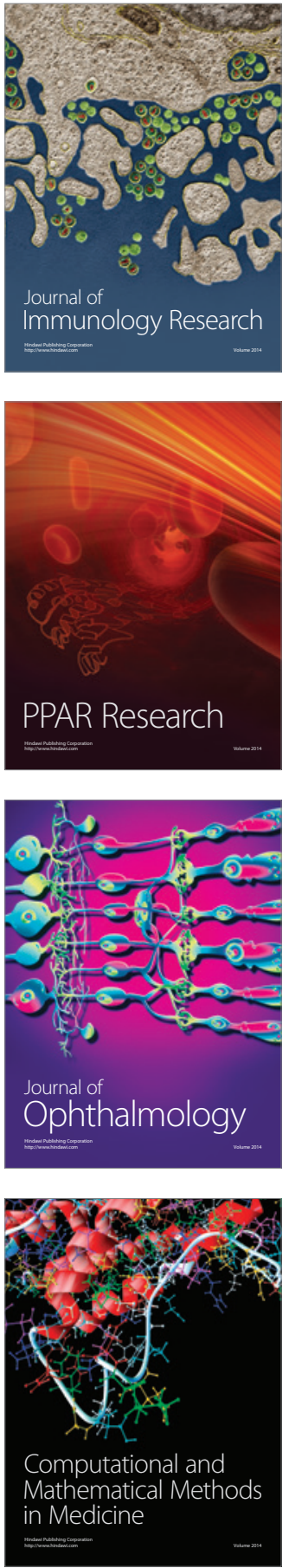

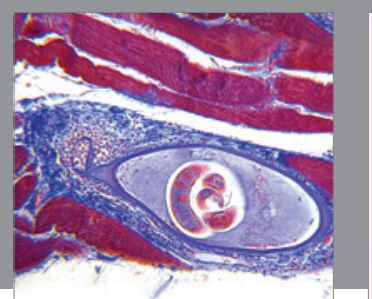

Gastroenterology Research and Practice

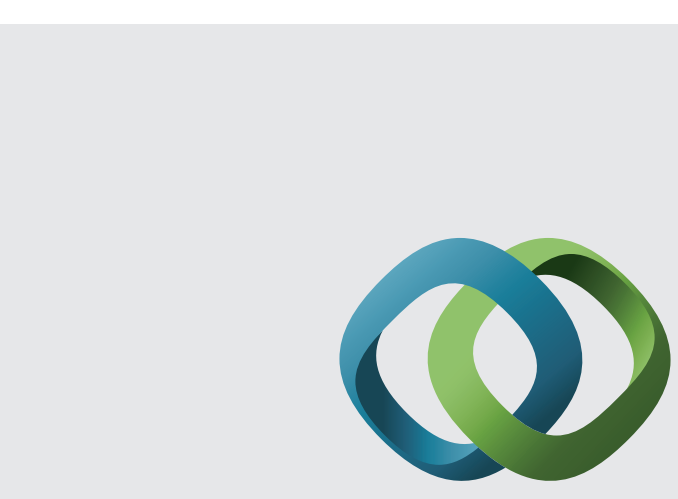

\section{Hindawi}

Submit your manuscripts at

http://www.hindawi.com
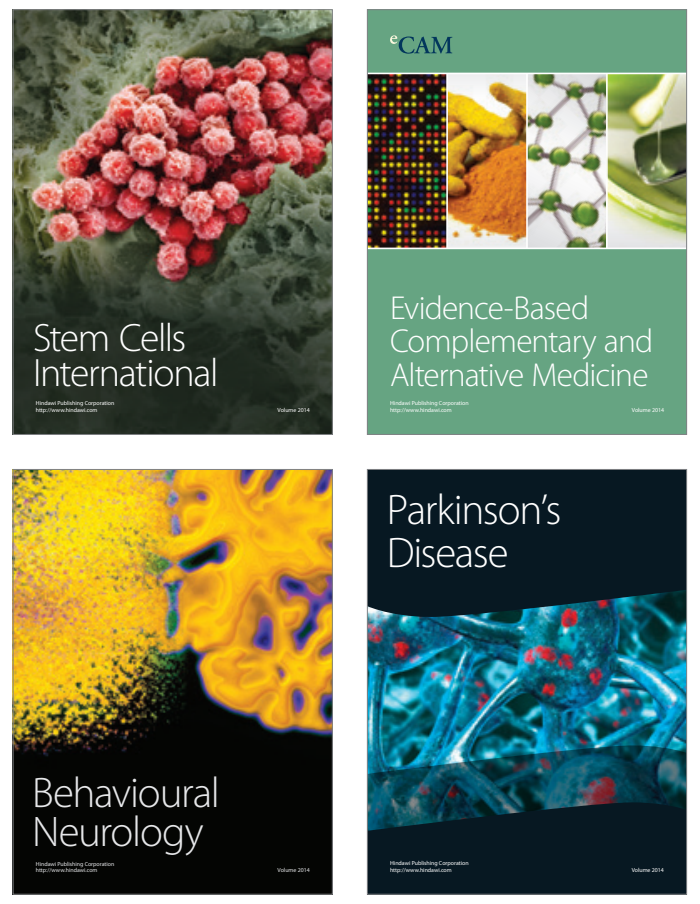
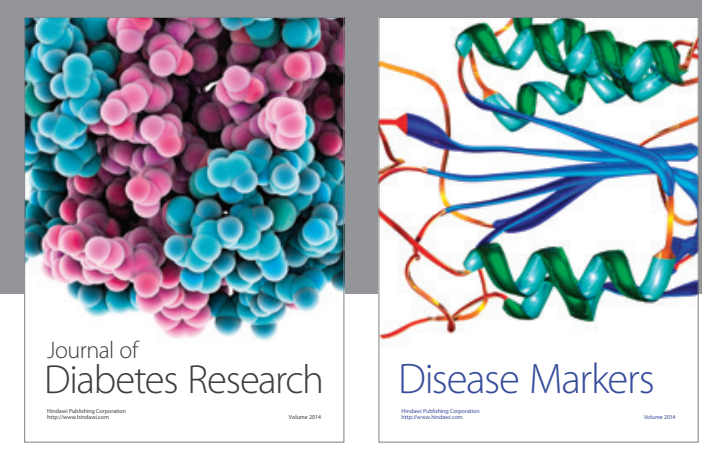

Disease Markers
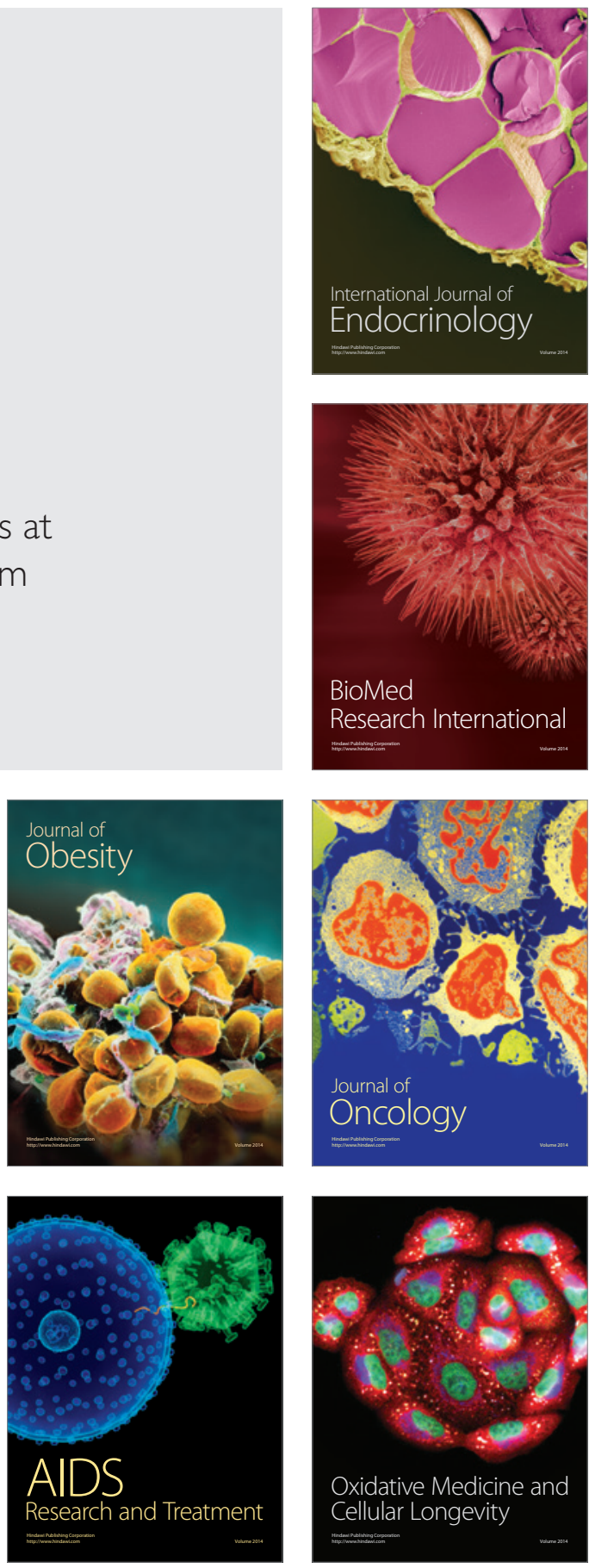